\title{
California perennial grasses are physiologically distinct from both Mediterranean annual and perennial grasses
}

\author{
Kurt J. Vaughn • Carmen Biel • Jeffrey J. Clary • Felicidad de Herralde • \\ Xavier Aranda • Richard Y. Evans • Truman P. Young • Robert Savé
}

Received: 3 December 2010 /Accepted: 21 February 2011/Published online: 5 March 2011

(C) The Author(s) 2011. This article is published with open access at Springerlink.com

\begin{abstract}
In the Central Valley of California, native perennial grass species have been largely replaced by Eurasian annual species, while in many parts of the Mediterranean Basin native perennial grasses continue to dominate, even on disturbed or degraded sites. We assessed whether differences in summer rainfall patterns have lead to the development of different plant-water strategies between grasses from these two regions. We compared six measures of plant-water physiology for three guilds of grasses: California perennial grasses, Mediterranean perennial grasses, and Mediterranean annual grasses. Discriminant analysis distinguished between the three guilds; Mediterranean perennial grasses were characterized by a more conservative water-relations physiology than Mediterranean annual grasses, whereas California perennial grasses were in some ways intermediate between the two Mediterranean grass guilds. For individual traits, California perennial grasses were either intermediate or more like Mediterranean annuals than Mediterranean perennials. Our results suggest California perennials are more drought tolerant than Mediterranean annuals but less drought
\end{abstract}

Responsible Editor: Rafael S. Oliveira.

K. J. Vaughn $(\bowtie) \cdot$ J. J. Clary $\cdot$ R. Y. Evans $\cdot$ T. P. Young

Department of Plant Sciences, University of California,

Davis, CA 95616, USA

e-mail: kjvaughn@ucdavis.edu

C. Biel · F. de Herralde · X. Aranda • R. Savé IRTA, Horticultura Ambiental, Torre Marimon, 08140 Caldes de Montbui (Barcelona), Spain tolerant than Mediterranean perennials, despite the fact that California's Central Valley has a more intense summer drought than the Mediterranean Basin. These patterns may help explain why Mediterranean annuals, but not Mediterranean perennials, have been more successful invaders of interior California grasslands.

Keywords Drought avoidance · Drought tolerance · Invasion · Plant water relation $\cdot$ Poaceae

\section{Introduction}

The grasslands of California and the Mediterranean Basin have shown contrasting responses to anthropogenic disturbance and introductions of new species. In the Central Valley of California, native perennial grass species have been largely replaced by Eurasian annual species, while in many parts of the Mediterranean Basin native perennial grasses continue to dominate, even on disturbed or degraded sites. Although species from both regions endure summer drought stress typical of Mediterranean-type climate zones (Terradas and Savé 1992; Rundel 1998; Mooney and Hobbs 2000), the average inland California summer is long and rainless, while most of Iberia experiences a shorter and less intense summer drought (Clary 2008). These differing ecological contexts may lead to different strategies for water capture and use between species originating from these two regions. 
Plants have evolved an array of adaptations to deal with the seasonal water stress associated with Mediterranean-type climates. These adaptations have resulted in a diversity of growth forms and life histories, including a) deep-rooted evergreen trees, shrubs and grasses that maintain their leaves through summer dry periods, b) drought-deciduous trees and shrubs that lose all or part of their leaves during summer, and c) winter annual geophytes, grasses and herbs that escape seasonal water limitation by completing their annual cycles before summer (Ehleringer and Mooney 1982). In addition, Mediterranean climates differing in severity of summer drought may produce variable adaptive responses. We predict that grasses with different growth forms and life history as well as from regions with differing summer rainfall regimes, will exhibit different leaf ecophysiological traits (Hinckley et al. 1980; Davis and Mooney 1986; Rhizopoulou and Mitrakos 1990; Abril and Hanano 1998; Salleo and Nardini 2000; Serrano et al. 2005; Galmes et al 2007).

Differences in life history strategies may also contribute to the competitive superiority of exotic annuals in California. Annual species are often able to escape drought by limiting growth to periods with high soil water potentials and by completing their life cycle before dry summer conditions. Perennials may also confine the majority of their growth to times with favorable soil water conditions but must then survive periods of low water potentials. Therefore, the strong seasonal rainfall patterns typical of Central Valley grasslands may favor the competitive superiority of annuals (Raunkiaer 1934; Jackson and Roy 1986; Blumler 1993). Recent studies have suggested that before the invasion of Eurasian annual grass species, parts of the Central Valley did indeed support a high diversity of native annuals; however, these species were mostly forbs, not grasses (Schiffman 2007; Minnich 2008).

In a test of a hypothesis first put forward by Jackson (1985), Clary (2008) has shown that in the Mediterranean basin, the relative abundance of annual grasses was strongly correlated with increasing seasonality of precipitation (but not mean yearly precipitation). Annuals tended to dominate sites that received very little rainfall in the summer, while perennials were found in sites that received some summer rainfall. This pattern can also be observed in the invasion of California grasslands; Regions with intense summer drought (e.g.. the Central Valley) have been more thoroughly invaded by annual species than the coastal prairies of California, which have a less intense summer drought and are often still dominated by perennial grasses (Clary 2006).

Theories that have been proposed to explain the conversion of California's Central Valley to Mediterranean annual grasslands fall into two broad categories that differ in their mechanisms for invasion and continued dominance. The first category maintains that sustained natural or anthropogenic disturbances, such as drought and/or overgrazing (Heady et al. 1992; Burcham 1957), altered the competitive relationship between native California perennial grasses and Mediterranean annual grasses sufficiently to achieve a complete state transition (sensu Briske et al. 2005). The current dominance of Mediterranean annual grasses in this case, even in the absence of continued disturbance, is attributed to the inherent priority effects of site domination (e.g. via seed saturation or alteration of nutrient or water cycles). Theories in the second category suggest that Mediterranean annual species are better adapted to California's Central Valley conditions than the native perennial species (Jackson 1985). Their successful invasion and continued dominance are attributed to competitive superiority due to traits such as earlier germination (Chiariello 1989) and faster growth and physiological adaptations that increase resource capture (Dyer and Rice 1999).

Interspecific competition in xeric systems such as Mediterranean-type climate grasslands is most typically for water (Terradas and Savé 1992; Dyer and Rice 1999), and gradients in moisture availability are often linked with levels of invasion within plant communities (Rejmanek 1989), including within some California grasslands (Thomsen et al. 2006). Differences in relative capacities to capture, conserve, and use water likely play an important role in the relative success of perennial grasses in the presence of annual competitors. Many of these water relation strategies are linked to measurable morphological and physiological characteristics (Alscher and Cumming 1990; Chapin 1991; Reich et al. 2003).

In this study, we examined physiological traits in a suite of perennial grass species native to Mediterranean climate zones of Spain and California, as well as a group of Mediterranean annual grasses that are invasive in California. Our goal was to seek region-specific or guild-specific patterns in water-use strategy, specifically in drought tolerance. 
We hypothesized that California perennials should show more morphological and physiological traits characteristic of drought tolerant species than their Eurasian counterparts, since the summer drought is consistently longer and drier in California than in the Mediterranean Basin. A drought tolerance strategy would correspond to low rates of water loss to nonphotosynthetically related processes, such as cuticular transpiration (Svenningsson and Liljenberg 1986), as well as lower relative water content at turgor loss point, reflecting capacity to maintain turgor under drought stress conditions (Hinckley et al. 1983). Drought-tolerant species often show higher resistance to hydraulic flow through roots than drought avoiders and escapers (Lo Gullo and Salleo 1988; Lo Gullo et al. 1998), as well as lower stomatal conductance in well watered conditions ( Filella et al. 1998; Gratani and Varone 2004; Gulias et al. 2002; Lo Gullo and Salleo 1988). In addition, we predicted that morphological characteristics, such as specific leaf weight and leaf width, would be consistent with other drought tolerant species. Drought tolerant species often have leaves with a decreased surface area to volume ratio, in order to limit evaporative water loss from leaves, resulting in relatively high specific leaf weights and narrow leaves (Bittman and Simpson 1989; Alscher and Cumming 1990). Thus, we predicted California perennials, relative to Mediterranean annuals and perennials, would demonstrate the following traits related to drought tolerance: lower cuticular transpiration, lower relative water content at turgor loss point, higher rate of root hydraulic resistance, lower stomatal conductance, higher specific leaf weight, and narrower leaf width.

\section{Materials and methods}

We measured six ecophysiological parameters on leaves and roots from three guilds of $\mathrm{C}_{3}$ grasses grown with optimal water availability: ten native California perennial grass species, five Mediterranean perennial grasses, and six Mediterranean annual grasses that are invasive in California grasslands (Table 1).

Grasses were grown under greenhouse conditions in containers at the IRTA-Cabrils facility in Catalonia, Spain $\left(41^{\circ} 31^{\prime} 32^{\prime \prime} \mathrm{N}, 2^{\circ} 22^{\prime} 07^{\prime \prime} \mathrm{E}\right)$. Seed was field collected for all perennial species and annual seed was obtained from Valley Seed (Fresno, California, USA). We sowed all species between late March and early April, and data were collected between June and July. We seeded each species into three litre pots filled with a 2:1 (by volume) mixture of peat (Floragard TKS-1) and perlite (Europerl A-13). An automatic irrigation system with $2 \mathrm{~L} / \mathrm{h}$ drippers irrigated each pot at an initial rate of $100 \mathrm{~mL} / \mathrm{d}$, gradually increasing to $400 \mathrm{~mL} / \mathrm{d}$ as the plants grew. To insure adequate irrigation we measured substrate moisture by integrated time domain reflectometry (TDR) using a TRIME (IMKO GmbH, Germany) device. Plants were not fertilized; no signs of nutrient deficiencies were observed. Air temperature of the greenhouse was recorded every $30 \mathrm{~min}$ by a Hobo (Onset Computer Corporation, Bourne, Massachusetts). Mean, maximum, and minimum temperatures were $21.7^{\circ} \mathrm{C}, 31.6^{\circ} \mathrm{C}$ and $14.6^{\circ} \mathrm{C}$, respectively.

From these plants we measured five ecophysiological parameters associated with drought tolerance. Leaf area for one mature leaf from six replicate plants per species was determined from computer imaging of harvested leaves (Digital Image Analysis System, Delta-T, United Kingdom). Specific leaf weight (SLW) was then calculated by dividing each ovendried weight by the corresponding leaf area. Leaf width at the middle of the leaf length (Width) was also calculated for five leaves from each of six individuals per species with the Digital Image Analysis System (Delta-T, United Kingdom).

Cuticular transpiration rates $\left(\mathrm{mg} \mathrm{H} \mathrm{H}_{2} \mathrm{O} \cdot \mathrm{m}^{-2} \cdot \mathrm{min}^{-1}\right.$, $\mathrm{TRc}$ ) were measured on detached leaves after natural desiccation caused stomatal closure (Svenningsson and Liljenberg 1986). TRc for each species were determined gravimetrically from one large leaf from each of six individuals - generally the second youngest fully expanded leaf. Relative water content at turgor loss point $\left(\mathrm{RWC}_{\mathrm{tlp}}\right)$ was then estimated from the graphs of cuticular transpiration rate over time (Serrano et al. 2005).

To measure the resistance to hydraulic flow through roots (Hendry and Grime 1993), we carefully washed the roots of 5 replicates from each species to remove the growth medium. Root hydraulic resistance, as measured by the Ramos and Kaufmann (1979) method, provides information on the physiological ability of roots to absorb and transport water independent of soil hydraulic conductivity, soil electrical conductivity, soil/plant interface, and soil 
Table 1 List of species and abbreviations by tribe and guild

\begin{tabular}{|c|c|c|c|}
\hline Grass Guild & Grass Tribe & Species & Abbreviation \\
\hline \multirow[t]{10}{*}{ California perennials } & Aveneae & Calamagrstis nutkaensis & $\mathrm{Cn}$ \\
\hline & Aveneae & Koeleria macrantha & $\mathrm{Km}$ \\
\hline & Meliceae & Melica californica & $\mathrm{Mc}$ \\
\hline & Poeae & Festuca californica & $\mathrm{Fc}$ \\
\hline & Poeae & Festuca idahoensis & $\mathrm{Fi}$ \\
\hline & Poeae & Poa secunda & Ps \\
\hline & Stipeae & Nassella lepida & $\mathrm{Nl}$ \\
\hline & Stipeae & Nassella pulchra & $\mathrm{Np}$ \\
\hline & Triticeae & Elymus glaucus & $\mathrm{Eg}$ \\
\hline & Triticeae & Leymus triticoides & $\mathrm{Lt}$ \\
\hline \multirow[t]{5}{*}{ Medtiterranean perennials } & Brachypodieae & Brachypodium phoenicoides & $\mathrm{Bp}$ \\
\hline & Brachypodieae & Brachypodium retusum & $\mathrm{Br}$ \\
\hline & Poeae & Dactylis glomerata & $\mathrm{Dg}$ \\
\hline & Stipeae & Stipa gigantea & $\mathrm{Sg}$ \\
\hline & Stipeae & Stipa tenacissima & St \\
\hline \multirow[t]{6}{*}{ Mediterranean annuals } & Aveneae & Avena fatua & Af \\
\hline & Poeae & Bromus diandrus & $\mathrm{Bd}$ \\
\hline & Poeae & Bromus hordeaceus & $\mathrm{Bh}$ \\
\hline & Poeae & Bromus tectorum & $\mathrm{Bt}$ \\
\hline & Poeae & Lolium multiflorum & $\mathrm{Lm}$ \\
\hline & Poeae & Vulpia myuros & $\mathrm{Vm}$ \\
\hline
\end{tabular}

temperature and/or oxygen concentration. Intact roots $15-30 \mathrm{~cm}$ in length were immersed in water inside a pressure chamber (Soil Moisture 3005, Santa Barbara, California), and the cut end of each root was passed through the pressure chamber opening and inserted into a $1 \mathrm{~mm}$ diameter flexible plastic tube. Air pressure of $0.5 \mathrm{MPa}$ was applied; the volume of water flowing through the roots, out of the chamber and into the tube was measured for three time intervals (between 1 and $3 \mathrm{~min}$ each), adjusted for the varying flux of each species. Hydraulic resistance was then calculated (see Ramos and Kaufmann 1979) as:

$\mathrm{Rh}=(\mathrm{P} \times \mathrm{L}) / \mathrm{J}$

where $\mathrm{Rh}$ is hydraulic resistance $\left(\mathrm{MPa} \cdot \mathrm{s} / \mathrm{cm}^{2}\right), \mathrm{P}$ is the applied pressure $(0.5 \mathrm{MPa}), \mathrm{L}$ is root length $(\mathrm{cm})$, and $\mathrm{J}$ is the flow of water $\left(\mathrm{cm}^{3} / \mathrm{s}\right)$. An estimate of $\mathrm{Rh}$ was possible for all five of the Mediterranean perennial grasses, for only four of the ten Californian species and two of the six Mediterranean annual species.
Concurrently, we ran a separate drought stress experiment on a subset of species grown in the same conditions as above to assess how stomatal conductance $\left(g_{s}\right)$ of species in these guilds is influenced by low soil water content. A drought cycle was applied to six replicates of ten species, two Mediterranean perennials (Brachipodium phoenicoides and Stipa gigantea), two Californian perennials (Nassella pulchra and Koeleria macrantha) and six Mediterranean annuals (Avena fatua, Bromus diandrus, Bromus hoerdeaceus, Bromus tectorum, Lolium multiflorum and Vulpia myorus). Due to facilities constraints, drought cycle was imposed to plants of perennial species in 2006 and to annuals in 2007. In July, with similar climatic conditions (mean temperature $24-25^{\circ} \mathrm{C}$, air relative humidity $60-75 \%$ ), drought was imposed by withdrawing irrigation to a group of six (perennials) or five (annuals) individuals, while maintaining irrigation to control groups with the same number of replicates. After 7 days, when soil water content had dropped from an initial $17 \%$ to less than $5 \%, \mathrm{~g}_{\mathrm{s}}\left(\mathrm{mmol} / \mathrm{m}^{2} \cdot \mathrm{s}\right)$ was measured on droughtstressed and well-watered individuals with a GFS3000 leaf gas exchange system (Walz $\mathrm{GmbH}$, Effeltrich, 
Germany) in 2006 and with a Li-1600 Porometer (LICOR, Lincoln, Nebraska, USA) in 2007.

Since the focus of this study was guild-level comparisons, we averaged across individuals of each species for each trait, and species means were used as replicates within the three guilds in the analyses (see Appendix 1). Values for Rh and SLW were $\ln$ transformed for normality in all analyses and the homogeneity of variances among guilds was assessed using Bartlett's test of homoscedasticity. We performed a MANOVA comparing the three guilds across the five measurements: TRc, RWC $\mathrm{Rlp}_{\text {tlp }}, \mathrm{Rh}, \mathrm{SLW}$ and Width. Stomatal conductance was excluded from the MANOVA because it does not represent a general trait as the former parameters, but the particular conditions of the date in which $g_{s}$ values were obtained. We then carried out one-way ANOVAs for each of the five measured traits separately, and did a posteriori comparisons among means using Tukey's honestly significant difference (HSD) correction for multiple comparisons. We also performed a discriminant analysis to assess whether the three grass guilds were distinct groupings. Due to missing data, $\mathrm{Rh}$ and leaf water conductance measurements were excluded from the discriminant analysis and the species were compared using the remaining four leaf measurements. For the drought stress experiment we performed a two-way ANOVA with guild and treatment as predictor variables and stomatal conductance as the response variable. We report the analysis without the interaction of guild and treatment as it was found to be non-significant $\left(F_{2,5}=\right.$ $0.17, P=0.85)$. All statistical analyses were performed using JMP 8.0 (SAS Institute Inc).

\section{Results}

The MANOVA revealed a significant difference among the three guilds for the five traits (Wilks' Lambda $_{10,8}=0.035, P=0.046$ ). For individual traits, California perennial grasses were often intermediate, or more like Mediterranean annuals than Mediterranean perennials (Fig. 1a-e). Specific leaf weight differed significantly among guilds $\left(F_{2,20}=15.09, P<0.0001\right)$, with California perennials demonstrating intermediate values (Fig. 1a). The analyses showed a significant difference in $\mathrm{Rh}\left(F_{2,10}=7.87, P=0.01\right)$, which statistically differentiated Mediterranean perennials from Mediterranean annuals and showed California peren- nials to be intermediate to both (Fig. 1b). For leaf width the ANOVA differentiated $\left(F_{2,20}=3.63, P=0.04\right)$ both Mediterranean perennials and Mediterranean annuals from California perennials (Fig. 1c). The ANOVA for $\mathrm{RWC}_{\text {tlp }}$ revealed that Mediterranean annuals are distinct $\left(F_{2,20}=5.18, P=0.02\right)$ from California perennials but not from Mediterranean perennials (Fig. 1d). The analysis showed TRc was not significantly different $\left(F_{2,20}=0.93, P=0.4\right)$ among guilds (Fig. 1e).

The analysis of the drought stress experiment revealed that the drought treatment significantly decreased stomatal conductance (Treatment $F_{1,16}=$ 5.42, $P=0.03$ ) equally across guilds (non-significant guild $\mathrm{x}$ treatment interaction). Mediterranean perennials had a significantly lower stomatal conductance (Guild $F_{2},{ }_{16}=4.95, P=0.02$ ) than Mediterranean annuals, and California perennials were intermediate to both (Fig. 2).

The discriminant analysis revealed that the three guilds occupied significantly distinct areas of the multivariate space (Wilks' Lambda $8,30=0.15, P=$ 0.0003; Fig. 3). Along the first canonical axis, which accounted for $65 \%$ of the variation, California perennial grasses were intermediate between Mediterranean annual and perennial grasses. This axis was strongly related to (ln-transformed) SLW and to a lesser degree with $\mathrm{RWC}_{\text {tlp }}$ and TRc (Table 2). The second canonical axis, most strongly correlated with $\mathrm{RWC}_{\text {tlp }}$ and width (Table 2), accounted for $35 \%$ of the variation and was associated with separation between the Mediterranean guilds and the California guild.

\section{Discussion}

Our hypothesis that California perennial grass species would show more morphological and physiological traits characteristic of drought tolerant species than their Mediterranean counterparts was only partially supported. In this study, Mediterranean perennials expressed physiological traits more consistent with higher drought tolerance than California perennial grasses (Figs. 1a-c, 2). Mediterranean perennials had significantly higher SLW, higher Rh and lower leaf width and stomatal conductance than California perennials. The two perennial guilds were statistically indistinguishable for $\mathrm{RWC}_{\mathrm{tlp}}$ and $\mathrm{TRc}$.

Mediterranean annual grasses expressed traits that suggest a lower drought tolerance than both California 

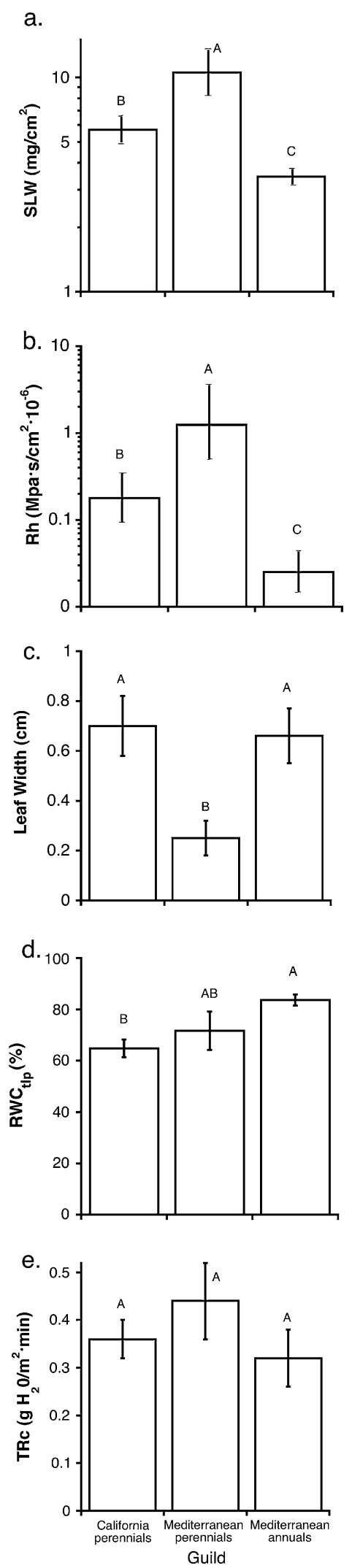

Fig. 1 Comparisons of means for five physiological measurements by guild. a specific leaf weight (SLW), b root hydraulic resistance $(\mathrm{Rh})$, $\mathbf{c}$ leaf width, $\mathbf{d}$ relative water content at turgor loss point $\left(\mathrm{RWC}_{\mathrm{tlp}}\right)$, and e cuticular transpiration rate $(\mathrm{TRc})$. Error bars are $+/-$ standard error. Guilds with different letters are significantly different by Tukey's HSD

and Mediterranean perennial grasses (Fig.1a-d). Mediterranean annuals had significantly lower SLW and Rh than both perennial guilds (Fig. 1a-b). Mediterranean annuals had significantly wider leaves (Fig. 1c) and higher stomatal conductance (Fig. 2) than Mediterranean perennials, and significantly higher $\mathrm{RWC}_{\mathrm{tlp}}$ than California perennials (Fig. 1d). The three guilds were statistically indistinguishable for TRc (Fig. 1e). The annual's lower drought tolerance may be related to their phenology: growth is limited to the cool, wet winters, which is typical of the "drought avoidance" strategy employed by annuals avoiding drought stress as seed (Raunkiaer 1934; Blumler 1984).

We found California perennials to be intermediate to Mediterranean annual and perennial grasses for two measurements: specific leaf weight and root hydraulic resistance (Fig. 1a-b). For two other measurements California perennial grasses were statistically differentiated from either Mediterranean annual grasses $\left(\mathrm{RWC}_{\text {tlp }}\right.$, Fig. 1d) or Mediterranean perennial grasses (leaf width, Fig. 1c, stomatal conductance, Fig. 2).

Similarly, the discriminant analysis placed California perennial grasses intermediately between Mediterranean annuals and perennials along the first canonical axis, which accounted for two thirds of the variability (Fig. 3). The first canonical axis of the discriminant analysis, driven mostly by specific leaf weight and to a lesser degree by $\mathrm{RWC}_{\mathrm{tlp}}$ and TRc (Table 2), suggests a

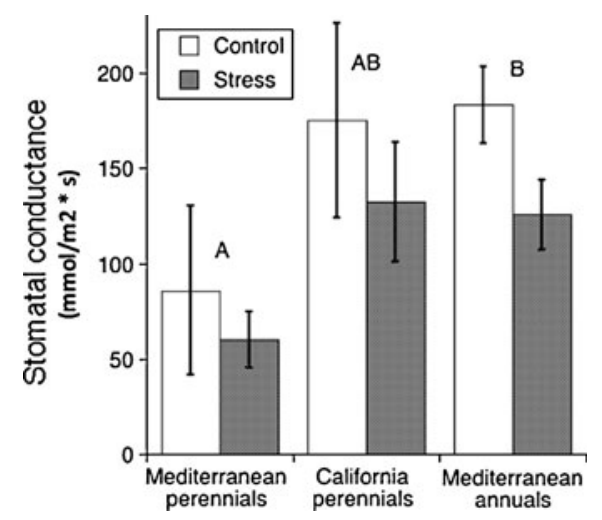

Fig. 2 Comparison of stomatal conductance $\left(g_{s}\right)$ for three guilds under watered and drought stressed conditions 
Fig. 3 Discriminant Analysis of the 21 species into three guilds using specific leaf weight (SLW), leaf width (Width), cuticular transpiration rate (TRc), and relative water content at turgor loss point $\left(\mathrm{RWC}_{\mathrm{tlp}}\right)$. The first canonical axis explains $65 \%$ of the variation while the second axis explains the remaining $35 \%$. The colored circles represent the $95 \%$ confidence limits for each group's mean. The green circles represent

Mediteranean annuals (MA), the blue triangles Mediteranean perennials (MP) and the red squares California perennials (CP). For species abbreviations see Table 1

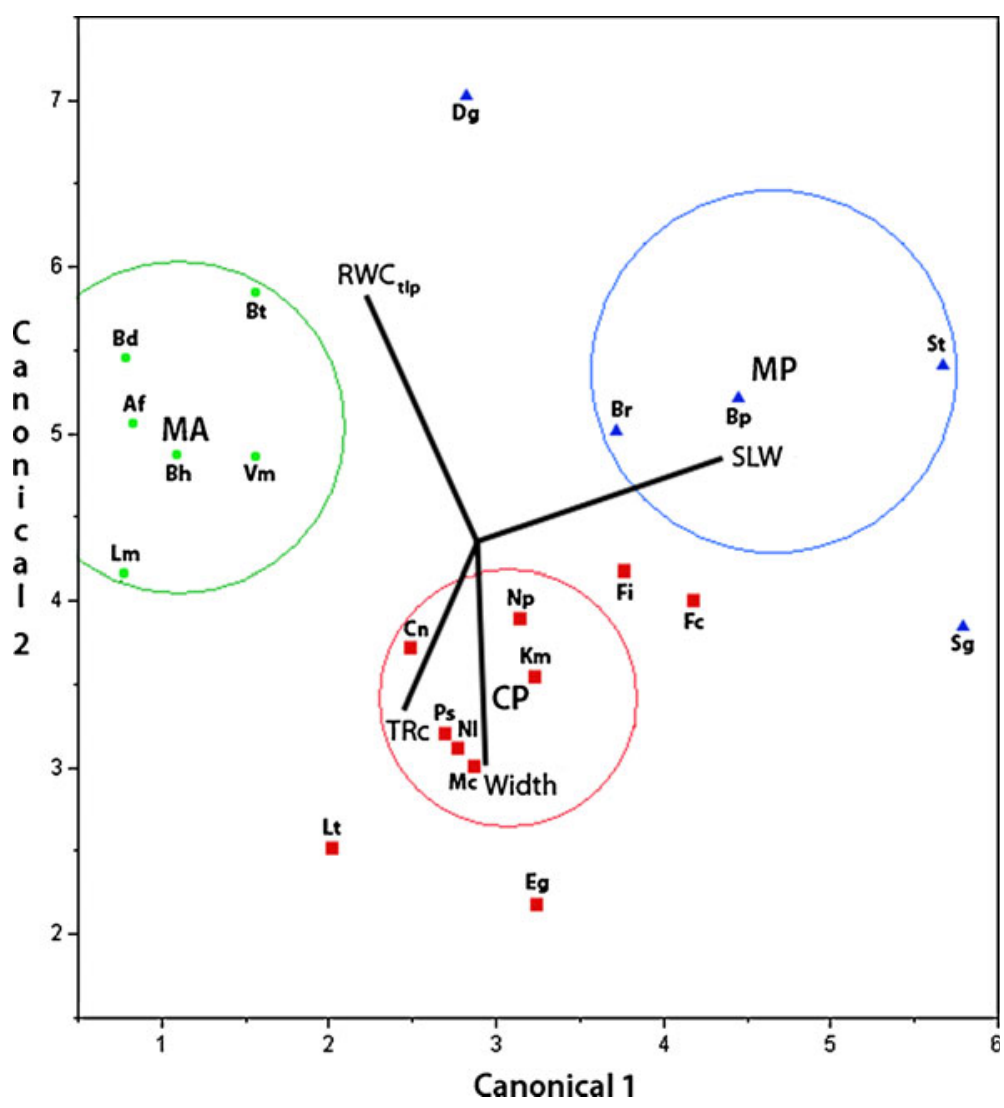

gradient in drought tolerance across these three guilds of grasses.

Although both axes are formed by parameters related to drought tolerance, the first axis represents more of the variation and better reflects drought tolerance than the second axis. All three of the traits

Table 2 Correlation coefficients between the canonical axes and (ln-transformed) specific leaf weight (SLW), relative water content at turgor loss point $\left(\mathrm{RWC}_{\mathrm{tlp}}\right)$, cuticular transpiration rate (TRc), and leaf width (Width). Each trait is followed by our prediction of how that trait should correlate, positively $(+)$ or negatively $(-)$, with drought tolerance. Note all three of the traits that strongly correlate with Canonical 1 have the predicted direction of correlation, while the direction of correlation of the traits does not agree for Canonical 2

\begin{tabular}{lcc}
\hline Trait (correlation) & Canonical 1 & Canonical 2 \\
\hline SLW (+) & 0.96 & 0.18 \\
$\operatorname{RWC}_{\text {tlp }}(-)$ & -0.48 & 0.64 \\
TRc (-) & -0.35 & -0.36 \\
Width (-) & 0.06 & -0.53 \\
\hline
\end{tabular}

that most strongly correlate with the first canonical axis do so in the direction predicted by a theoretical drought tolerance axis (Table 2). For example, we predicted that drought-tolerant species would demonstrate low values of $\mathrm{RWC}_{\text {tlp }}$ and therefore this trait should be negatively correlated with a hypothetical drought tolerance value. The second canonical axis of the discriminant analysis is less instructive with respect to drought tolerance, as it seems to be more related to the geographical origin of the guilds (Table 2).

Taken together our results suggest California perennials are more drought tolerant than Mediterranean annuals but less able to tolerate drought than Mediterranean perennials, despite the fact that California's Central Valley has a more intense summer drought than the Mediterranean Basin. This apparent contradiction may be explained through differences in life history strategies. California perennials carry out almost all of their growth and reproduction during winter and spring, when soil water is generally available (Chiariello 1989), then become fully dormant to avoid California's severe summer drought (Galmes et al. 2007; Clary 2008). In 
contrast, the occasional summer precipitation that characterizes the Mediterranean Basin favors species that can remain active during the summer, which requires greater drought tolerance adaptations.

In some ways adaptations of California perennial grasses appear to be similar to those of annual grasses, including the Mediterranean annuals that have successfully supplanted them in much of their original native range. In addition to the physiological differences in water capture and use described here, California perennial grass adaptations include a greater emphasis on earlier reproduction (Clary et al. 2005) and the ability to avoid severe summer droughts through summer dormancy and leaf shedding. These data suggest that California perennial grasses represent a drought stress strategy intermediate between drought tolerant Mediterranean perennials and drought escaping annuals; they are able to tolerate some drought stress, but rely on drought avoidance to survive the summer.

This finding may help explain the conversion of California's Central Valley perennial grasslands to Mediterranean annual grasslands. If strong summer drought in the Mediterranean basin favors annual grasses (Clary 2008) and the annual strategy can be seen as an extreme strategy of drought avoidance, then California's intense summer droughts should also favor strong drought avoiders. Since California perennial grasses represent a strategy in some ways intermediate between tolerance and avoidance, they may be competitively inferior, under intense summer drought stress, to better drought avoiders (i.e. Mediterranean annuals). Therefore, Mediterranean annual grasses may have become dominant in and continue to dominate California's Central Valley because they are better adapted to withstand the summer drought than the native perennial grasses.

Conditions of high soil water availability may limit the explanatory power of the plant-water physiological measurements reported in this study, as many of them are known to be strongly affected by water availability (Hinckley et al. 1980; Davis and Mooney 1986; Rhizopoulou and Mitrakos 1990; Abril and Hanano 1998; Salleo and Nardini 2000; Serrano et al. 2005; Galmes et al 2007). Thus, the values reported here may differ substantially from those that may be obtained under field (drier) conditions. While we would expect low water availability to alter the mean values of TRc, $\mathrm{RWC}_{\mathrm{tlp}}$, Rh, SLW and Width for each guild, we would also expect dry conditions to increase the relative differences of these traits between guilds (Hinckley et al. 1980; Davis and Mooney 1986; Rhizopoulou and Mitrakos 1990; Abril and Hanano 1998; Salleo and Nardini 2000; Serrano et al. 2005; Galmes et al 2007). We then consider our measurements under well-watered conditions to be under estimates of drought tolerance for these species and a conservative estimate of differences in drought tolerance between guilds. Since our results demonstrated differences between these guilds, even under high water conditions, we take these findings to be indicative of the robustness of the descriptive power of these parameters. Additionally, results from the leaf water conductance study measured along a drought cycle in a subset of species, show differences between guilds consistent with all other parameters.

Our findings support the hypothesis that Mediterranean annual grasses have an innate adaptive advantage to the Central Valley's rainfall regime and do not support the state transition model which postulates that an initial widespread disturbance allowed for an initial invasion of annuals and that continued dominance is maintained through priority effects. The adaptive advantage of Mediterranean annuals to summer drought may have led to a strong enough competitive advantage to explain the displacement of native California perennials, even in the absence of disturbance. This argument is also consistent with the observation that California perennials continue to dominate in coastal regions, where the summer drought stress is less intense.

This line of reasoning also raises the question: if the climate of California's Central Valley favors drought avoidance then why is the native flora not dominated by annuals? The simplest explanation is that native annuals were indeed widespread in the Central Valley, but they were forbs, not grasses (Schiffman 2007; Minnich 2008). This explanation, however, does not account for the fact that annual grasses are underrepresented in California's native grass flora.

Another possible reason for the dominance of perennial species in the California native grass flora is the fairly regular occurrence of a prolonged mid-winter drought in California (Null 2006). Hamilton et al. (1999) simulated this phenomenon and found that drought stress during the growing season had a greater negative effect on exotic annual grass seedling biomass than on native perennial seedlings. If drought stress 
during the winter growing season favors perennials over annuals, this hypothesis may account for the underrepresentation of native annual grasses in the California flora.

Here we suggest the possibility that the evolution of drought avoidance in California perennial grasses may have partially pre-empted the annual grass niche. The Mediterranean climate of California is hypothesized to have developed an increasingly severe summer drought throughout the Pleistocene (Axelrod 1973). The native perennial grasses favored by higher levels of summer rain early in the Pleistocene may have slowly adapted to this climatic shift by accumulating traits consistent with drought avoidance. Competition from California perennial grasses, which behave in many ways like annual grasses, as well as competition from annual forbs, may then have precluded the evolution of more California annual grass species.

In any case, our results show a clear tendency for California's native perennials grass species to have ecophysiological traits that are more conservative than Mediterranean annuals and less conservative the Mediterranean perennials. A more formal analysis of life history traits (phenology, dormancy, growth rates, reproductive rates) across these three guilds may help us refine our understanding of the evolution of California's grass flora, as well as its extraordinary replacement by an exotic annual grass flora from the Mediterranean Basin.

Acknowledgments The authors thank W. Roberts and the University of California, Davis Arboretum for their expertise and S. Sprenkle and M. Wilkerson for valuable discussions and comments on the manuscript. This work was supported by the Elvenia Slosson Endowment and through a Global Invasives Network Research Coordination Network supported research exchange (NSF Grant number 0541673).

Open Access This article is distributed under the terms of the Creative Commons Attribution Noncommercial License which permits any noncommercial use, distribution, and reproduction in any medium, provided the original author(s) and source are credited.

\section{Appendix 1}

Mean and standard error (in parentheses) of individuals for each measurement across species for each guild: California Perennials (CP), Mediterranean Perennials (MP) and Mediterranean Annuals (MA). Measurements are relative water content at turgor loss point $\left(\mathrm{RWC}_{\mathrm{tlp}}\right)$, specific leaf weight (SLW), cuticular transpiration rate (TRc), leaf width (Width), root hydraulic resistance $(\mathrm{Rh})$, stomatal conductance $\left(\mathrm{g}_{\mathrm{s}}\right)$ and stomatal conductance under drought stress conditions (Stressed $\mathrm{g}_{\mathrm{s}}$ ).

\section{References}

Abril M, Hanano R (1998) Ecophysiological responses of three evergreen woody Mediterranean species to water stress. Acta Oecologica 19:377-387

Alscher RG, Cumming JR (1990) Stress responses in plants: adaptation and acclimation mechanisms. Wiley-Liss, New York

Axelrod DI (1973) History of the mediterranean ecosystem in California. In: di Castri F, Mooney HA (eds) Mediterranean-type ecosystems: origin and structure. Springer, Berlin, pp 225-277

Bittman S, Simpson GM (1989) Drought effects on water relations of 3 cultivated grasses. Crop Sci 29:992-999

Blumler E (1984) Climate and the annual habit. Master's Thesis, University of California, Berkeley, CA, USA

Blumler MA (1993) Some myths about California grasslands and grazers. Fremontia 20:22-27

Briske DD, Fuhlendorf SD, Smeins FE (2005) State-and-transition models, thresholds, and rangeland health: a synthesis of ecological concepts and perspectives. Rangeland Ecol Manage 58:1-10

Burcham LT (1957) California range land: an historicoecological study of the range resource in the Sacramento Valley of California. Division of Forestry, Department of Natural Resources, Sacramento

Chapin FS (1991) Integrated responses of plants to stress. Bioscience 41:29-36

Chiariello NR (1989) Phenology of California grasslands. In: Huenneke LF, Mooney H (eds) Grassland structure and function: California annual grassland. Kluwer Academic Publishers, Dordrecht, pp 45-58

Clary JJ (2006) Distribution and ecophysiological adaptations of annual and perennial grasses in mediterranean climate zones of California and the Iberian Peninsula. Ph.D. dissertation, University of California, Davis, CA, USA

Clary JJ (2008) Rainfall seasonality determines annual/perennial grass balance in vegetation of Mediterranean Iberia. Plant Ecol 195:13-2

Clary JJ, Biel C, Savé R (2005) Ecophysiology of California and Mediterranean grass species: implications for restoration of xeric grasslands. The World Conference on Ecological Restoration Conference Abstracts. Society for Ecological Restoration International Meeting, Zaragoza, p 50

Davis SD, Mooney HA (1986) Tissue water relations of four co-occurring chaparral shrubs. Oecologia 70:527-535

Dyer A, Rice KJ (1999) Effects of competition on resource availability and growth of a California bunchgrass. Ecology 80:2697-2710

Ehleringer J, Mooney HA (1982) Productivity of desertand Mediterranean-climate plants. In: Lange OL, Nobel PS, Osmond CB, Ziegler $\mathrm{H}$ (eds) Encyclopedia of plant 
physiology. Physiological plant ecology. Springer, Berlin, pp 205-231

Filella I, Llusia J, Pinol J, Penuelas J (1998) Leaf gas exchange and fluorescence of Phillyrea latifolia, Pistacia lentiscus and Quercus ilex saplings in severe drought and high temperature conditions. Environ Exp Bot 39:213-220

Galmés J, Flexas J, Savé R, Medrano H (2007) Water relations and stomatal characteristics of Mediteranean plants with different growth forms and leaf habits; responses to water stress and recovery. Plant Soil 290:139-155

Gratani L, Varone L (2004) Adaptive photosynthetic strategies of the Mediterranean maquis species according to their origin. Photosynthetica 42:551-558

Gulias J, Flexas J, Abadia A, Medrano H (2002) Photosynthetic responses to water deficit in six Mediterranean sclerophyll species: possible factors explaining the declining distribution of Rhamnus ludovici-salvatoris, an endemic Balearic species. Tree Physiol 22:687-697

Hamilton JG, Holzapfel C, Mahall BE (1999) Coexistence and interference between a native perennial grass and non-native annual grasses in California. Oecologia 121:518-526

Heady HF, Bartolome JW, Pitt MD, Savelle GW, Stroud MC (1992) California prairie. In: Coupland RT (ed) World ecosystems: natural grasslands. Elsevier, New York, pp 313-335

Hendry GAF, Grime JP (1993) Methods in comparative plant ecology. Chapman \& Hall, London

Hinckley TM, Duhme F, Hinckley AR, Richter H (1980) Water relations of drought hardy shrubs: osmotic potential and stomatal reactivity. Plant Cell Environ 3:131-140

Hinckley TM, Duhme F, Hinckley AR, Richter H (1983) Drought relations of shrub species: assessment of the mechanisms of drought resistance. Oecologia 59:344-350

Jackson LE (1985) Ecological origins of California's Mediterranean grasses. J Biogeogr 12:349-361

Jackson LE, Roy J (1986) Growth patterns of Mediterranean annual and perennial grasses under simulated rainfall regimes of southern France and California. Acta Oecologia 7:191-212

Lo Gullo MA, Salleo S (1988) Different strategies of drought resistance in three Mediterranean sclerophyllous trees growing in the same environmental conditions. New Phytol 108:267-276

Lo Gullo MA, Nardini A, Salleo S, Tyree MT (1998) Changes in root hydraulic conductance of Olea oleaster seedlings following drought stress and irrigation. New Phytol 140:25-31

Minnich RA (2008) California's fading wildflowers. Lost legacy and biological invasions. University of California Press, Berkeley
Mooney HA, Hobbs RJ (2000) Invasive species in a changing world. Island, Washington D.C

Null J (2006) Mid-winter dry spells. URL http://ggweather.com/ enso/winter_dry_spells.htm (accessed on 10 November 2009)

Ramos C, Kaufmann MR (1979) Hydraulic resistance of rough lemon roots. Physiol Plant 45:311-314

Raunkiaer C (1934) The life forms of plants and statistical plant geography. Clarendon, Oxford

Reich PB, Wright I, Cavender-Bares J, Craine J, Oleksyn J, Westoby M, Walters M (2003) The evolution of plant functional variation: traits, spectra, and strategies. Int J Plant Sci 164:143-164

Rejmánek M (1989) Invasibility of plant communities. In: Drake JA, DiCastri F, Groves RH, Kruger FJ, Mooney HA, Rejmánek M, Williamson WH (eds) Ecology of biological invasions: A global perspective. Wiley, New York, pp 369-388

Rhizopoulou S, Mitrakos K (1990) Water relations of evergreen sclerophylls. I. Seasonal changes in the water relations of eleven species from the same environment. Ann Bot 65:171-178

Rundel PW (1998) Landscape disturbance in Mediterranean type ecosystems: an overview. In: Rundel PW, Montenegro G, Jaksic FM (eds) Landscape disturbance and biodiversity in Mediterranean type ecosystems. Springer, Berlin, pp 3-22

Salleo S, Nardini A (2000) Sclerophylly: evolutionary advantage or mere epiphenomenon. Plant Biosyst 134:247-259

Schiffman PM (2007) Species composition at the time of first European settlement. In: Stromberg MR, Corbin JD, D'Antonio CA (eds) California grasslands. University of California Press, Berkeley, pp 180-190

Serrano L, Peñuelas J, Ogaya R, Savé R (2005) Tissue-water relations of two co-occurring evergreen Mediterranean species in response to seasonal and experimental drought conditions. J Plant Res 118:263-269

Svenningsson M, Liljenberg C (1986) Changes in cuticular transpiration rate and cuticular lipids of oat (Avena sativa) seedlings induced by water stress. Physiol Plant 66:9-14

Terradas J, Savé R (1992) Summer-winter double stress and water relationships as clue factors in the distribution of Quercus ilex. Vegetatio 99-100:137-145

Thomsen MA, D'Antonio CM, Suttle KB, Sousa WP (2006) Ecological resistance, seed density and their interactions determine patterns of invasion in a California coastal grassland. Ecol Lett 9:160-170 